\title{
Clinical characteristics and outcome of very elderly patients $\geq 90$ years in intensive care: a retrospective observational study
}

\author{
Sophie Becker ${ }^{1 \dagger}$, Jakob Müller ${ }^{1,2 \dagger}$, Geraldine de Heer ${ }^{1}$, Stephan Braune ${ }^{1}$, Valentin Fuhrmann \\ and Stefan Kluge ${ }^{1 *}$
}

\begin{abstract}
Background: Since the overall prognosis of very elderly patients is generally limited, admissions to intensive care in these patients are often restricted. Therefore, only very few information is available on the prognosis of nonagenarians after intensive care treatment. The aim of this study was to analyze the clinical characteristics and outcomes of very elderly patients ( $\geq 90$ years) admitted to an intensive care unit (ICU).

Methods: Monocentric, retrospective observational study of all patients aged $\geq 90$ years admitted to the Department of Intensive Care Medicine with a total capacity of 132 ICU beds at the University Medical Center Hamburg in Germany between January 2008 and June 2013. A multivariate Cox regression analysis was used to identify risk factors for 28-day outcome.

Results: A total of 372 patients $\geq 90$ years of age were admitted to one of the departments ICUs. The majority of patients (66.7 \%) were admitted as an emergency admission, of which half underwent unscheduled surgery. $39.8 \%$ of patients required support by mechanical ventilation and vasoactive drugs, and $1.9 \%$ of patients received renal replacement. ICU and hospital mortality rates were 18.3 and 30.9\%, respectively. Overall survival at 1 year after hospital discharge was $34.9 \%$. Multivariate Cox regression analysis revealed creatinine, bilirubin, age, and necessity of catecholamines as independent risk factors and scheduled surgery as protective factor for 28-day outcome.

Conclusion: Nearly $70 \%$ of patients aged $\geq 90$ years were discharged alive from hospital following treatment at the $I C U$, and more than half of them were still alive 1 year after their discharge. The results suggest that 1-year survival prognosis of very old ICU patients is not as poor as often perceived and that age per se should not be an exclusion criterion for ICU admission.
\end{abstract}

Trial registration: WF-0561/13

Keywords: Intensive care, Prognosis, Long- term outcome, Over 90 years old

\section{Background}

As a result of demographic transition, the proportion of elderly and very elderly patients is increasing in industrial countries. Especially the percentage of the oldest patients ( $>80$ years) is growing among the elderly population

\footnotetext{
*Correspondence: skluge@uke.de

†Sophie Becker and Jakob Müller contributed equally to this manuscript

1 Department of Intensive Care Medicine, University medical center

Hamburg-Eppendorf, Martinistr. 52, 20246 Hamburg, Germany

Full list of author information is available at the end of the article
}

[1]. In 2030, the worldwide number of nonagenarians ( $\geq 90$ years) is expected to reach 30 million [2].

Medical progress increasingly allows elderly patients to undergo procedures and operations that only a few decades ago were not feasible because of age $[3,4]$. As a result, more very elderly patients are admitted to intensive care units (ICU). However, there is evidence that older patients have a poorer prognosis than younger patients [5-7]. Since the overall prognosis of very elderly patients is generally limited, ICU admissions in these patients are often restricted. Among intensivists and in 
the literature, the discussion about the appropriateness of ICU admissions of elderly patients is controversial [7-10], due to costs, limited resources, and questionable outcome.

Although international publications indicate that people 80 years of age and older already represent $15 \%$ of all ICU patients $[5,11]$, there is still a lack of information on prognosis and outcome, especially the older the patient is. Only few studies on elderly patients in intensive care have included nonagenarians, who if included, only accounted for a small proportion of the study population. Especially long-term outcomes have not been studied.

This study investigated, to the best of our knowledge, the largest cohort of nonagenarians treated in the ICU and aims to analyze a large cohort of $\geq 90$-year-old patients and their outcomes and risk factors influencing outcome.

\section{Methods}

\section{Setting}

The University Medical Center Hamburg-Eppendorf is a tertiary-level medical center with 1460 hospital beds and a volume of more than 80,000 in-patients per year. The Department of Intensive Care Medicine includes 11 ICUs with a total capacity of 132 ICU beds. Approximately, 8000 patients are admitted to the department per year, with an average length of stay in the ICU of 4.5 days. The Department of Intensive Care Medicine serves all adult critically ill patients of the university hospital and offers the maximum level of treatment to medical and surgical ICU patients.

\section{Study design}

All patients $\geq 90$ years admitted to our department between 1 January 2008 and 30 June 2013 were eligible for study inclusion. If a patient was admitted to the ICU several times, this was considered as one case, and admission data only for the first ICU admission were analyzed. The following data were extracted from the electronic patient data management system [Intregrated Care Manager $\odot$ (ICM), Dräger Medical, Lübeck, Germany]: Age, gender, place of residence, the presence of an advance directive, main reason of admission, comorbidities, length of ICU and hospital stay, treatment modalities and organ support (mechanical ventilation, use of catecholamines, renal replacement therapy, blood transfusions, antibiotics), discharge information, ICU- and hospital mortality as well as the occurrence of withholding life support.

Severity of illness was assessed using the Simplified Acute Physiology Score II (SAPS II). ICU and hospital mortality were analyzed, and the main outcome variable was 28 -day mortality. ICU mortality rates were compared to those of all patients between 80 and 89 years admitted to the ICU during the study period.
To obtain survival data at 1 year after hospital discharge, we contacted survivors or their relatives by phone. If the patient or the next of kin could not be contacted, information was obtained from the patients' general practitioner, their nursing homes, or the registration office.

The study was approved by the institutional review board (ethics committee of the Hamburg Chamber of Physicians, WF-0561/13). Due to the retrospective character of the study, patient's consent was not necessary according to local requirements.

\section{Statistics}

Data are presented either as median and interquartile ranges (IQR) or as absolute numbers with percentages. Binary variables were compared with Chi Square-Analysis or Fisher's exact, as appropriate. Metric variables were compared with the Mann-Whitney-U-Test. 28-day survival was assessed using the Kaplan-Meier method and Cox proportional hazard regression model. The KaplanMeier method was used to estimate survival curves, and log-rank test was used to test for differences between survival curves. The results of the Cox proportional hazard regression analysis are expressed with hazard ratios (HR). We included following parameters in the analysis: sex, scheduled surgery, unscheduled surgery, medical admission, mechanical ventilation, catecholamine therapy, renal replacement therapy, age, $\mathrm{pH}$, leukocytes, creatinine, bilirubin, and hemoglobin. Parameters that were significant in prediction for 28-day mortality in the univariate analysis $(\mathrm{p}<0.05)$ were included in the multivariate analysis. A two-sided $p$ value of $<0.05$ was considered statistically significant. Statistical analysis was conducted using IBM SPSS Statistics Version 20.0.

\section{Results}

A total of 34,392 patients were treated in the Department of Intensive Care Medicine during the study period. A total of $372(1.1 \%)$ patients were $\geq 90$ years old. The median age was 92.2 years (IQR 91.0-94.2), and the proportion of female patients was $66.7 \%$. Before ICU admission, 230 patients (61.8\%) lived at home, 128 (34.4 \%) in nursing homes, and 14 (3.7 \%) at assisted living facilities.

248 patients $(66.7 \%)$ were admitted to the ICU as an emergency admission, of which $50 \%$ underwent unscheduled surgery. $33.3 \%$ of patients $(n=124)$ were admitted following elective surgery. Trauma (28.8\%), cardiac diseases $(21.5 \%)$, and gastrointestinal diseases $(10.5 \%)$ were the most frequent causes of ICU admission. A detailed list of all patients' characteristics is shown in Table 1 . The average SAPS II score within $24 \mathrm{~h}$ of ICU admission was 36 (IQR 29-48). $90.9 \%$ of patients were 
Table 1 Patient characteristics

\begin{tabular}{|c|c|c|c|c|}
\hline Characteristics & All patients & ICU survivors & ICU-non-survivors & $\mathrm{p}$ value \\
\hline Number & 372 & 304 & 68 & \\
\hline Age (years), MD (IQR) & $92.2(91-94.3)$ & $92.2(90.9-94.4)$ & $92.3(91-93.3)$ & 0.858 \\
\hline Female, n (\%) & $248(66.7)$ & $211(69.4)$ & $37(54.4)$ & 0.018 \\
\hline Unplanned surgery, n (\%) & $121(32.5)$ & $101(33.2)$ & $20(29.4)$ & 0.544 \\
\hline Planned surgery, n (\%) & $124(33.3)$ & $117(38.5)$ & $7(10.3)$ & $<0.001$ \\
\hline Medical, n (\%) & $127(34.1)$ & $86(28.3)$ & $41(60.3)$ & $<0.001$ \\
\hline SAPS II, MD (IQR) & $36(29-48)$ & $34(28-43)$ & $55(44.8-65.8)$ & $<0.001$ \\
\hline \multicolumn{5}{|l|}{ Admission source, $n(\%)$} \\
\hline Normal ward & $227(61.0)$ & $195(64.1)$ & $32(47.1)$ & 0.009 \\
\hline Emergency room & $127(34.1)$ & $97(31.9)$ & $30(44.1)$ & 0.055 \\
\hline Other hospital & $18(4.8)$ & $12(3.9)$ & $6(8.8)$ & 0.09 \\
\hline \multicolumn{5}{|l|}{ Admission diagnosis, n (\%) } \\
\hline Trauma & $107(28.8)$ & $100(32.9)$ & $7(10.3)$ & $<0.001$ \\
\hline Cardiac surgery & $43(11.6)$ & $39(12.8)$ & $4(5.9)$ & 0.105 \\
\hline Abdominal surgery & $39(10.5)$ & $31(10.2)$ & $8(11.8)$ & 0.703 \\
\hline CPR & $26(7.0)$ & $13(4.3)$ & $13(19.1)$ & $<0.001$ \\
\hline Sepsis & $30(8.1)$ & $19(6.3)$ & $11(16.2)$ & 0.007 \\
\hline Pneumonia & $11(3.0)$ & $7(2.3)$ & $4(5.9)$ & 0.115 \\
\hline Myocardial infarction & $18(4.8)$ & $13(4.3)$ & $5(7.4)$ & 0.285 \\
\hline Arrhythmia and heart failure & $19(5.1)$ & $15(4.9)$ & $4(5.9)$ & 0.748 \\
\hline Neurologic & $22(5.9)$ & $15(4.9)$ & $7(10.3)$ & 0.09 \\
\hline Cerebral hemorrhage & $6(1.6)$ & $2(0.7)$ & $4(5.9)$ & 0.012 \\
\hline Pulmonary embolism & $5(1.3)$ & $5(1.6)$ & 0 & 0.589 \\
\hline Surgical, miscellaneous ${ }^{\mathrm{a}}$ & $41(11.0)$ & $38(12.5)$ & $3(4.4)$ & 0.054 \\
\hline Others (medical) ${ }^{b}$ & $21(5.6)$ & $16(5.3)$ & $5(7.4)$ & 0.582 \\
\hline \multicolumn{5}{|l|}{ Comorbidity, n (\%) } \\
\hline Arterial hypertension & $246(66.1)$ & $204(67.1)$ & $42(61.8)$ & 0.4 \\
\hline Cardiac diseases $^{c}$ & $185(49.7)$ & $150(49.3)$ & $35(51.5)$ & 0.751 \\
\hline Chronic heart failure & $82(22.0)$ & $65(21.4)$ & $17(25.0)$ & 0.515 \\
\hline Cardiac arrhythmia & $116(31.2)$ & $95(31.3)$ & $21(30.9)$ & 0.953 \\
\hline Valvular heart diseases & $38(10.2)$ & $31(10.2)$ & $7(10.3)$ & 0.981 \\
\hline Coronary heart disease & $95(25.5)$ & $75(24.7)$ & $20(29.4)$ & 0.418 \\
\hline Chronic renal insufficiency & $83(22.3)$ & $64(21.1)$ & $19(27.9)$ & 0.217 \\
\hline Neurodegenerative disease & $79(21.2)$ & $68(22.4)$ & $11(16.2)$ & 0.259 \\
\hline Diabetes & $47(12.6)$ & $40(13.2)$ & $7(10.3)$ & 0.521 \\
\hline Respiratory diseases & $45(12.1)$ & $32(10.5)$ & $13(19.1)$ & 0.079 \\
\hline Cancer & $28(7.5)$ & $23(7.6)$ & $5(7.4)$ & 0.952 \\
\hline Skeletal system disorders & $39(10.5)$ & $31(10.2)$ & $8(11.8)$ & 0.703 \\
\hline Thyroid disorders & $39(10.5)$ & $35(11.5)$ & $4(5.9)$ & 0.171 \\
\hline Mental disorders & $18(4.8)$ & $15(4.9)$ & $3(4.4)$ & 0.856 \\
\hline
\end{tabular}

ICU intensive care unit, MD median, IQR interquartile range, CPR Cardiopulmonary resuscitation

a surgical interventions on the spine, blood vessels, skin, and the head and neck region

b Renal failure, side-effects of medication, electrolyte imbalance, vascular diseases and diseases of the head and neck region, conservatively treated gastrointestinal bleeding

c Cases of $>1$ heart diseases were regarded as $n=1$

anemic $(\mathrm{Hb}<13 \mathrm{~g} / \mathrm{dl}$ for men, $<12 \mathrm{~g} / \mathrm{dl}$ for woman), $51.5 \%$ of patients presented with leucocytosis $(>11.5$ $\mathrm{Mrd} / \mathrm{l}$ ), and 46.7 and $22.9 \%$ showed elevated levels of serum-creatinine and -bilirubin $(>1.1 \mathrm{mg} / \mathrm{dl})$, respectively. Acidosis occurred in $53.2 \%$ of cases within $24 \mathrm{~h}$ after ICU admission. 


\section{Clinical course}

The median length of stay in the ICU and in the hospital was 1.4 days (IQR $0.8-2.7$ ) and 11 days (IQR 7-17), respectively. A total of 148 patients $(39.8 \%)$ were mechanically ventilated, of these 34 (9.1\%) were on non-invasive ventilation. Catecholamine support was applied in 148 patients (39.8\%). 25 patients (6.7 \%) developed acute renal failure and of these 7 patients $(1.9 \%)$ received renal replacement therapy during their ICU stay (Table 2). Five of these patients had been on intermittent hemodialysis for end-stage renal disease already prior to hospital admission. 114 patients $(30.6 \%)$ required antibiotic therapy.

\section{Short-term outcomes}

ICU and hospital mortality were 18.3 and $30.9 \%$, respectively.

Non-survivors had higher severity of disease as illustrated by SAPS II (55.8 vs. 36.1$)$, were more likely to be male ( 25 vs. $14.9 \%$ ), and had more frequent unscheduled surgery or medical reasons for ICU admission (Table 1). Annual mortality rates are presented in Fig. 1.

In-patients who were admitted twice $(\mathrm{n}=28)$, hospital mortality was $45.5 \%$. Five patients $(1.3 \%)$ were admitted three times and had a mortality rate of $80 \% .65$ patients $(17.5 \%)$ had an advance directive. The decision to withhold or withdraw therapy was made in 92 patients $(24.7 \%)$. The main area of withholding therapy was preexisting or subsequently made "Do Not Resuscitate" (73.8 \%) and "Do Not Intubate" (47.8 \%) orders.

In a Cox regression proportional hazard analysis in regard to 28-day survival creatinine, bilirubin, age, and necessity of catecholamine therapy were independent risk factors for worse 28-day outcome; scheduled surgery was a protective factor. Details are illustrated in Table 3a and 3b.

147 patients $(55.1 \%)$ were transferred to other hospitals either for further treatment or rehabilitation before moving to their final discharge destination. Details of outcomes and discharge destinations are shown in Table 4.

\section{ICU-outcome in the $\mathbf{8 0 - 8 9}$ age group}

2234 octogenarians were admitted to the ICU in the same period, which account for $6.5 \%$ of all ICU admissions.
The median age was 85.6 years (IQR 83.9-87.4), 1288 $(57.7 \%)$ were female. Median length of stay was 1.8 days (IQR 0.9-4.0), ICU mortality was $16.6 \%(\mathrm{n}=370)$. ICU mortality did not differ significantly between nonagenarians and octogenarians $(\mathrm{p}=0.412)$.

\section{Mid- and long-term outcomes}

Long-term survival follow-up (Fig. 2) was available for 242 of 257 hospital survivors (94.2\%) and overall 357 patients. 3 months and 1 year after discharge, 196 patients $(52.7 \%)$ and 130 patients $(34.9 \%)$ of the initial study population were still alive. Surgical patients had a better one-year survival than patients admitted for medical reasons (planned surgery: $48.4 \%$, unplanned surgery: $33.1 \%$ vs. $23.6 \%$ (medical), $\mathrm{p}<0.001$ ).

The impact of selected factors in regard to 1 year survival is illustrated in Table 5.

\section{Discussion}

This study evaluated the characteristics and outcomes of the largest cohort of nonagenarians in ICU published to date and provided data on their long-term survival.

Despite the fact that elderly patients are increasingly been treated in the intensive care environment, there is a lack of information available about their prognosis and outcome.

The $81.7 \%$ ICU-, $70 \%$ hospital-, and $35 \%$ one-year survival rates stand in contrast to and challenge widespread beliefs about the poor short- and long-term prognosis of nonagenarians admitted to the ICU. Especially the hospital mortality rates of patients undergoing planned surgery were remarkably low, whereas the outcome worsened after unplanned ICU admission and especially after ICU readmission. Within the group of nonagenarians, creatinine, bilirubin, age, and necessity of catecholamine therapy cause of admission were independent factors for 28-day outcome. Not surprisingly, the 18.3 \% ICU mortality of the study group of very elderly ICU patients was higher than that of the departments overall ICU mortality of $9 \%$. This age-related mortality risk is in line with many other outcome studies on a wide variety of critically ill ICU populations. Whereas several studies have identified age as an independent risk factor for ICU mortality

Table 2 procedures on ICU

\begin{tabular}{lccccc}
\hline Procedure, $\mathbf{n}(\%)$ & All patients & length $(\mathbf{h}) \mathbf{M D}(\mathbf{I Q R})$ & ICU survivors & ICU-non-survivors & $\mathbf{p}$ value \\
\hline Mechanical ventilation & $148(39.8)$ & $12.5(4.5-34)$ & $91(29.9)$ & $57(83.8)$ & $<2(76.5)$ \\
Catecholamines & $148(39.8)$ & $20(7-43.75)$ & $96(31.6)$ & $19(27.9)$ & $<0.001$ \\
Blood transfusion & $76(20.4)$ & & $57(18.8)$ & $4(5.9)$ & 0.089 \\
Renal replacement & $7(1.9)$ & $3(1)$ & $63(92.6)$ & 0.007 \\
Total & $213(57.3)$ & & $150(49.3)$ & $<0.001$ \\
\hline
\end{tabular}

$I C U$ intensive care unit, $M D$ median, $I Q R$ interquartile range 


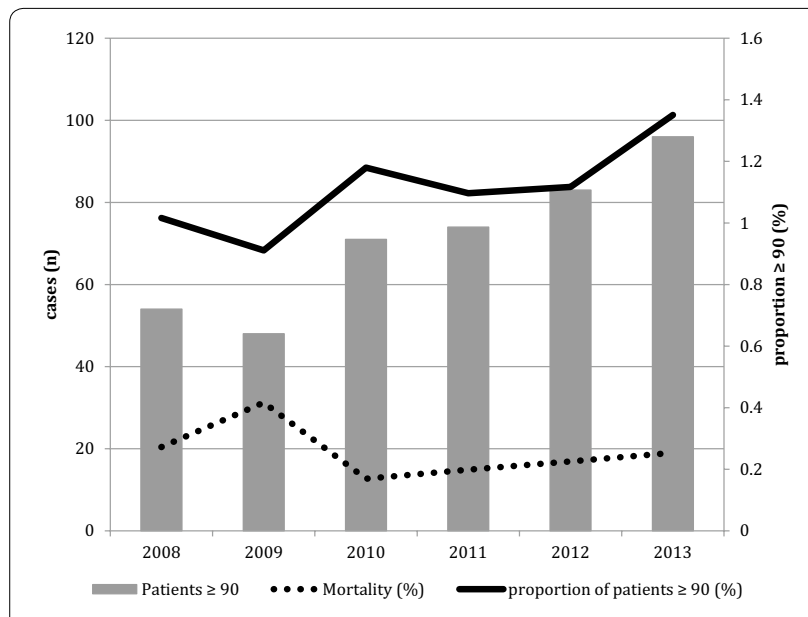

Fig. 1 Trends in admission and mortality. Absolute number, mortality, and proportion of nonagenarians in intensive care over time

Table 4 Clinical course and outcome

\begin{tabular}{lcc}
\hline Results & n & $\%$ \\
\hline ICU mortality $^{\text {a }}$ & 68 & 18.3 \\
Hospital mortality $^{\text {a }}$ & 115 & 30.9 \\
Unplanned surgery & 46 & 38 \\
Planned surgery & 15 & 12.1 \\
Medical admission & 54 & 42.5 \\
Withholding and/or withdrawal of therapy & 93 & 25 \\
Discharge destination & & \\
Home & 122 & 47.5 \\
Nursing care facilities & 101 & 39.3 \\
Short-term nursing care & 17 & 6.6 \\
Unknown & 17 & 6.6 \\
28-day mortality & 149 & 40.1 \\
90-day mortality & 176 & 47.3 \\
1-year mortality & 242 & 65.1 \\
\hline a The latest stay was considered for calculation & & \\
ICU intensive care unit & &
\end{tabular}

Table 3 Cox regression proportional hazard analysis for factors influencing 28-day survival

\begin{tabular}{|c|c|c|}
\hline Variables & Hazard-ratio (95 \% Cl) & p value \\
\hline \multicolumn{3}{|c|}{ Univariate analysis for 28-day outcome } \\
\hline Planned surgery & $0.242(0.143-0.409)$ & $<0.001$ \\
\hline Medical admission & $2.156(1.515-3.068)$ & $<0.001$ \\
\hline Unplanned surgery & $1.357(0.945-1.948)$ & 0.098 \\
\hline Mechanical ventilation & $3.186(2.216-4.58)$ & $<0.001$ \\
\hline Catecholamines & $2.602(1.819-3.722)$ & $<0.001$ \\
\hline Renal replacement & $1.379(0.438-4.335)$ & 0.583 \\
\hline Age & $1.085(1.022-1.151)$ & 0.008 \\
\hline Sex (female) & $0.753(0.524-1.081)$ & 0.124 \\
\hline $\mathrm{pH}$ & $0.829(0.626-1.097)$ & 0.189 \\
\hline Leukocytes & $1.032(1.007-1.0579$ & 0.01 \\
\hline Creatinine & $1.328(1.168-1.511)$ & $<0.001$ \\
\hline Hemoglobin & $0.97(0.872-1.079)$ & 0.576 \\
\hline Bilirubin & $1.435(1.186-1.736)$ & $<0.001$ \\
\hline \multicolumn{3}{|c|}{ Multivariate analysis for 28-day outcome } \\
\hline Planned surgery & $0.439(0.225-0.856)$ & 0.016 \\
\hline Medical & $1.125(0.665-1.902)$ & 0.661 \\
\hline Mechanical ventilation & $1.513(0.819-2.796)$ & 0.186 \\
\hline Catecholamines & $2.224(1.195-4.139)$ & 0.012 \\
\hline Age & $1.14(1.045-1.243)$ & 0.003 \\
\hline Leukocytes & $1.017(0.986-1.049)$ & 0.276 \\
\hline Creatinine & $1.224(1.033-1.45)$ & 0.02 \\
\hline Bilirubin & $1.281(1.046-1.569)$ & 0.017 \\
\hline
\end{tabular}

Cl Confidence interval

All parameters at ICU admission

$[6,7,12-16]$, other studies have found the severity of illness and comorbidities to be more important risk factors than age itself $[5,17-20]$.

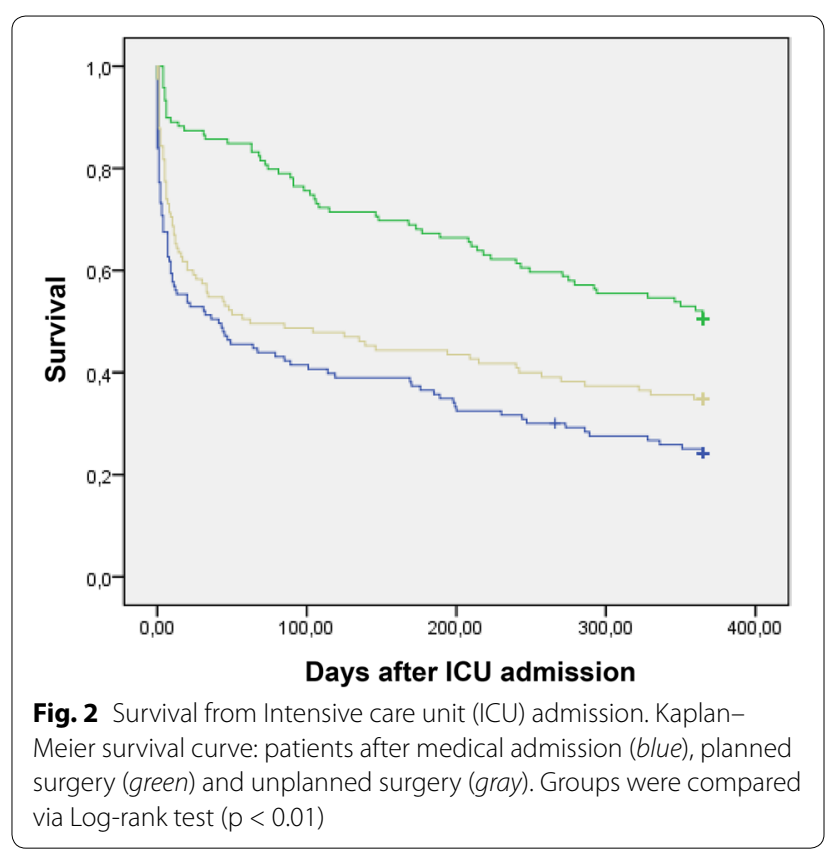

Analyzing data from a large Austrian database $(\mathrm{n}=17,126)$, Ihra et al. found a significantly higher hospital mortality rate in patients older than 80 years in comparison to patients younger than 80 years (31.0 vs. $15.9 \%$ [5]. Only few observational studies have analyzed the outcome of the nonagenarians ( $\geq 90$ years). Demoule et al. examined 36 patients $\geq 90$ years in a French ICU. ICU and hospital mortality were 28 and $47 \%$, respectively [21]. Rellos et al. analyzed 60 patients $\geq 90$ years in a Greek ICU, which accounted for $1.1 \%$ of all ICU 
Table 5 Factors influencing long-term survival

\begin{tabular}{|c|c|c|c|}
\hline Parameter & $\begin{array}{l}1 \text { year } \\
\text { survivors }\end{array}$ & $\begin{array}{l}\text { 1-year } \\
\text { non-survivors }\end{array}$ & $p$ value \\
\hline Age (years), median (IQR) & $92.9(92-95.4)$ & $91.4(90.7-93.1)$ & 0.101 \\
\hline Female (\%) & 75.4 & 61.2 & 0.006 \\
\hline Unplanned surgery (\%) & 30.8 & 33 & 0.659 \\
\hline Planned surgery (\%) & 46.2 & 26 & $<0.001$ \\
\hline Medical (\%) & 23.1 & 41 & 0.001 \\
\hline \multicolumn{4}{|l|}{ Admission diagnosis } \\
\hline Trauma (\%) & 33.8 & 25.6 & 0.095 \\
\hline Gastrointestinal (\%) & 12.3 & 8.4 & 0.229 \\
\hline Tumor (\%) & 10.0 & 9.7 & 0.925 \\
\hline Pulmonary (\%) & 3.8 & 7.5 & 0.168 \\
\hline Neurological (\%) & 3.8 & 7.9 & 0.13 \\
\hline $\begin{array}{l}\text { Cardiopulmonary } \\
\text { resuscitation (\%) }\end{array}$ & 3.1 & 9.3 & 0.028 \\
\hline Cardiac (\%) & 24.6 & 18.1 & 0.14 \\
\hline Sepsis (\%) & 1.5 & 9.7 & 0.003 \\
\hline Others & 6.9 & 4 & 0.219 \\
\hline \multicolumn{4}{|l|}{ Comorbidity } \\
\hline Arterial hypertension (\%) & 70.0 & 63.9 & 0.24 \\
\hline Cardiac diseases (\%) & 47.7 & 50.7 & 0.589 \\
\hline Chronic heart failure (\%) & 19.2 & 22.9 & 0.416 \\
\hline Cardiac arrhythmia (\%) & 27.7 & 33.9 & 0.223 \\
\hline Valvular heart disease (\%) & 12.3 & 8.4 & 0.229 \\
\hline $\begin{array}{l}\text { Chronic renal insuf- } \\
\text { ficiency }(\%)\end{array}$ & 14.6 & 25.6 & 0.016 \\
\hline $\begin{array}{l}\text { Neurodegenerative } \\
\text { diseases (\%) }\end{array}$ & 21.8 & 78.2 & 0.002 \\
\hline Diabetes (\%) & 13.1 & 12.8 & 0.935 \\
\hline Respiratory diseases (\%) & 7.7 & 14.5 & 0.056 \\
\hline Cancer (\%) & 5.4 & 8.8 & 0.239 \\
\hline $\begin{array}{l}\text { Skeletal system disorders } \\
(\%)\end{array}$ & 9.2 & 11 & 0.595 \\
\hline Thyroid disorders (\%) & 16.2 & 7.5 & 0.011 \\
\hline Mental disorders (\%) & 1.5 & 7 & 0.022 \\
\hline \multicolumn{4}{|l|}{ Procedures on ICU } \\
\hline $\begin{array}{l}\text { Mechanical ventilation } \\
\text { (\%) }\end{array}$ & 26.2 & 47.6 & $<0.001$ \\
\hline Catecholamines (\%) & 29.2 & 45.8 & 0.002 \\
\hline Blood transfusion (\%) & 14.6 & 24.2 & 0.031 \\
\hline $\begin{array}{l}\text { Renal replacement } \\
\text { therapy (\%) }\end{array}$ & 0.8 & 2.6 & 0.219 \\
\hline SAPS 2, median (IQR) & $33(28-44)$ & $42(33-53)$ & $<0.001$ \\
\hline $\mathrm{pH}$, median (IQR) & $7.35(7.29-7.45)$ & $7.34(7.25-7.45)$ & $<0.001$ \\
\hline Bilirubin, median (IQR) & $0.7(0.5-1.1)$ & $0.8(0.5-1.1)$ & 0.406 \\
\hline Hemoglobin, median (IQR) & $9.8(8.6-10.8)$ & $9.6(8.2-10.7)$ & 0.016 \\
\hline Leukocytes, median (IQR) & $11.9(8.4-15.7)$ & $11.3(8.4-15.5)$ & 0.048 \\
\hline Creatinine, median (IQR) & $1.1(0.8-1.4)$ & $1.2(0.9-1.8)$ & $<0.001$ \\
\hline
\end{tabular}

admissions. The average length of stay in ICU and hospital was 5 and 23 days, respectively, with an ICU mortality of $20 \%$ [22]. Other studies with data of patients $>85$ years demonstrated ICU mortality rates ranging from 14.6 [6] to $36.6 \%$ [7].

The comparability between all these studies is limited by differences in the study settings and health care systems resulting in different ICU admission policies and practices. Additionally, some studies analyzed predominantly elderly patients with unplanned ICU admissions [6], explaining differences in mortality rates between studies. In contrast, the present study included all very elderly patients treated in the ICU. One possible contributing reason for a higher mortality rate in elderly ICU patients is the fact that the decision to limit or withhold therapy occurs more frequently among elderly ICU patients. Accordingly, Seder et al. found increasing rates of withholding and withdrawal of life support in the ICU with advanced age [23], and Al-Dorzi et al. observed a more frequent application of Do Not Resuscitate- orders in patients $>80$ years [24]. In line with these previous findings, we recorded a quarter of very elderly ICU patients not receiving maximal therapy on the basis of an advanced directive and/or a presumed poor prognosis.

Patients admitted to the ICU following scheduled surgery had lower mortality rates than patients with unscheduled admission. Correspondingly, other studies observed the best outcome in the scheduled surgery group among very elderly patients [22, 25]. Additionally, admission for unplanned surgery was a predictor for poor outcome [25]. The differences in mortality between the three subgroups can be partly explained by the severity of acute illness. Accordingly, we observed the highest mortality rates in patients following medical admission.

At present, the average life expectancy of a 90-yearold German person is 3.8 years for men and 4.3 years for woman, and life expectancy at an age of 95 years still is 2.7 to 3 years [26]. Approximately, one-third of our entire study population was still alive at 1 year after ICU discharge. Similar findings were made by recent studies with one-year survival rates among elderly ICU patients ranging from 28 to $56 \%$ [25, 27-30].

Limited ICU resources are one of the main reasons for controversial discussions about the accessibility of intensive care treatment for elderly patients [9]. However, findings of the recently published ELDICUS study suggest that of all patients, elderly subjects have a high benefit from ICU treatment [12].

Our study cohort represented only $1.1 \%$ of all departmental ICU admissions from 2008 to 2013. However, the proportion of elderly patients is expected to constantly rise as a result of the demographic transition and this will also affect intensive care medicine $[5,11]$. Thus, intensivists will increasingly have to cope with the special challenges of an increasingly aging ICU population and related aspects, such as multimorbidity, polypharmacy, and ethical questions. Our patients were hospitalized mainly for traumatic causes and cardiovascular diseases. Corresponding findings were made by prior studies [5-7, 
11], especially the incidence of cardiovascular diseases particularly increases with advanced age [31].

The results of our study have to be interpreted with caution due to the following limitations: Because of the single-center study design, results may not be generalizable to other settings. The relatively good survival rates of our nonagenarian ICU patients may have been the result of a preselection bias of restrictions to ICU admission decisions in this age group. This important aspect was outside the scope of this study. Furthermore, our follow-up data do not provide insights into quality of life and functional status after hospital discharge. Other study groups found, that both, quality of life and autonomy in activities of daily living among elderly ICU survivors were deemed to be satisfactory $[28,32]$. Further and larger multicenter studies on the long-term outcome of elderly ICU patients with regard to survival and quality of life are warranted.

\section{Conclusion}

Nearly $70 \%$ of patients aged $\geq 90$ years were discharged alive from hospital following treatment at the ICU and more than one-third were still alive 1 year after their discharge. The results suggest that long-term survival prognosis of very elderly ICU patients may be not as poor as often perceived. Chronological age per se should not be an exclusion criterion for ICU admission. Instead, the biological age, an achievable therapeutic goal and the patient's will ought to play a major role in the decisionmaking process. Then, intensive care treatment may be justified even for patients with shorter life expectancy than the general population.

\section{Abbreviations}

ICU: intensive care unit; IQR: interquartile range; Cl: confidence interval; ROC: receiver operating characteristic; SAPS II: Simplified Acute Physiology Score II; SPSS: Statistical Package for the Social Sciences.

\section{Authors' contributions \\ SB carried out the data acquisition, participated in the design of the study, and drafted the manuscript. JM contributed to data acquisition and in the design of the study and drafted the manuscript. VF performed and interpreted the statistical analysis and drafted the manuscript. GH and SB participated in its design and coordination and helped to draft the manuscript. SK conceived of the study, and participated in its design and coordination and revised the manuscript. All authors read and approved the final manuscript.}

\section{Author details}

${ }^{1}$ Department of Intensive Care Medicine, University medical center HamburgEppendorf, Martinistr. 52, 20246 Hamburg, Germany. ${ }^{2}$ Department of Anesthesia, University medical center Hamburg-Eppendorf, Hamburg, Germany.

\section{Acknowledgements}

None.

\section{Competing interests}

The authors declare that they have no competing interests.

Received: 5 July 2015 Accepted: 7 December 2015

Published online: 21 December 2015

\section{References}

1. Population Division. Department of Economic and Social Affairs, United Nations: World Population Ageing. 2013. [http://www.un.org/en/ development/desa/population/publications/pdf/ageing/WorldPopulationAgeing2013.pdf]. Accessed 30 June 2015.

2. Population Division. Department of Economic and Social Affairs, United Nations: Profiles of Ageing. 2013. [http://esa.un.org/unpd/popdev/AgingProfiles2013/default.aspx]. Accessed 30 June 2015.

3. Watters JM. Surgery in the elderly. Can J Surg. 2002;45(2):104-8.

4. Arenal JJ, de Teresa G, Tinoco C, Toledano M, Said A. Abdominal surgery in nonagenarians: short-term results. Surg Today. 2007;37(12):1064-7. doi:10.1007/s00595-007-3537-1.

5. Ihra GC, Lehberger J, Hochrieser H, Bauer P, Schmutz R, Metnitz B, et al. Development of demographics and outcome of very old critically ill patients admitted to intensive care units. Intensive Care Med. 2012;38(4):620-6. doi:10.1007/s00134-012-2474-7.

6. Fuchs L, Chronaki CE, Park S, Novack V, Baumfeld Y, Scott D, et al. ICU admission characteristics and mortality rates among elderly and very elderly patients. Intensive Care Med. 2012;38(10):1654-61. doi:10.1007/ s00134-012-2629-6.

7. Brunner-Ziegler S, Heinze G, Ryffel M, Kompatscher M, Slany J, Valentin A. "Oldest old" patients in intensive care: prognosis and therapeutic activity. Wien Klin Wochenschr. 2007;119(1-2):14-9. doi:10.1007/ s00508-007-0771-x.

8. Marik PE. Should age limit admission to the intensive care unit? Am J Hosp Palliat Care. 2007;24(1):63-6. doi:10.1177/1049909106295385.

9. Boumendil A, Somme D, Garrouste-Orgeas M, Guidet B. Should elderly patients be admitted to the intensive care unit? Intensive Care Med. 2007;33(7):1252-62. doi:10.1007/s00134-007-0621-3.

10. Nguyen YL, Angus DC, Boumendil A, Guidet B. The challenge of admitting the very elderly to intensive care. Ann Intensive Care. 2011;1(1):29. doi:10.1186/2110-5820-1-29.

11. Bagshaw SM, Webb SA, Delaney A, George C, Pilcher D, Hart GK, et al. Very old patients admitted to intensive care in Australia and New Zealand: a multi-centre cohort analysis. Crit Care. 2009;13(2):R45. doi:10.1186/ cc7768

12. Sprung CL, Artigas $A$, Kesecioglu J, Pezzi A, Wiis J, Pirracchio R, et al. The Eldicus prospective, observational study of triage decision making in European intensive care units. Part II: intensive care benefit for the elderly. Crit Care Med. 2012;40(1):132-8. doi:10.1097/CCM.0b013e318232d6b0.

13. Djaiani G, Ridley S. Outcome of intensive care in the elderly. Anaesthesia. 1997;52(12):1130-6.

14. Ely EW, Wheeler AP, Thompson BT, Ancukiewicz M, Steinberg KP, Bernard $G R$. Recovery rate and prognosis in older persons who develop acute lung injury and the acute respiratory distress syndrome. Ann Intern Med. 2002;136(1):25-36.

15. Soares M, Carvalho MS, Salluh Jl, Ferreira CG, Luiz RR, Rocco JR, et al. Effect of age on survival of critically ill patients with cancer. Crit Care Med. 2006;34(3):715-21. doi:10.1097/01.ccm.0000201883.05900.3f.

16. Rosenthal GE, Kaboli PJ, Barnett MJ, Sirio CA. Age and the risk of in-hospital death: insights from a multihospital study of intensive care patients. J Am Geriatr Soc. 2002;50(7):1205-12.

17. Lerolle N, Trinquart L, Bornstain C, Tadie JM, Imbert A, Diehl JL, et al. Increased intensity of treatment and decreased mortality in elderly patients in an intensive care unit over a decade. Crit Care Med. 2010;38(1):59-64. doi:10.1097/CCM.0b013e3181b088ec.

18. Somme D, Maillet JM, Gisselbrecht M, Novara A, Ract C, Fagon JY. Critically ill old and the oldest-old patients in intensive care: short- and longterm outcomes. Intensive Care Med. 2003;29(12):2137-43. doi:10.1007/ s00134-003-1929-2.

19. de Rooij SE, Abu-Hanna A, Levi M, de Jonge E. Factors that predict outcome of intensive care treatment in very elderly patients: a review. Crit Care. 2005;9(4):R307-14. doi:10.1186/cc3536.

20. Boumendil A, Maury E, Reinhard I, Luquel L, Offenstadt G, Guidet B. Prognosis of patients aged 80 years and over admitted in medical intensive care unit. Intensive Care Med. 2004;30(4):647-54. doi:10.1007/ s00134-003-2150-z.

21. Demoule A, Cracco C, Lefort Y, Ray P, Derenne JP, Similowski T. Patients aged 90 years or older in the intensive care unit. J Gerontol A Biol Sci Med Sci. 2005;60(1):129-32 
22. Rellos K, Falagas ME, Vardakas KZ, Sermaides G, Michalopoulos A. Outcome of critically ill oldest-old patients (aged 90 and older) admitted to the intensive care unit. J Am Geriatr Soc. 2006;54(1):110-4. doi:10.1111/j.1532-5415.2005.00544.x.

23. Seder DB, Patel N, McPherson J, McMullan P, Kern KB, Unger B, et al. Geriatric experience following cardiac arrest at six interventional cardiology centers in the United States 2006-2011: interplay of age, do-not-resuscitate order, and outcomes. Crit Care Med. 2014;42(2):289-95. doi:10.1097/ cCM.0b013e3182a26ec6.

24. Al-Dorzi HM, Tamim HM, Mundekkadan S, Sohail MR, Arabi YM. Characteristics, management and outcomes of critically ill patients who are 80 years and older: a retrospective comparative cohort study. BMC anesthesiology. 2014;14:126. doi:10.1186/1471-2253-14-126.

25. Andersen FH, Flaatten $\mathrm{H}$, Klepstad P, Romild U, Kvale R. Long-term survival and quality of life after intensive care for patients 80 years of age or older. Ann Intensive Care. 2015;5(1):53. doi:10.1186/s13613-015-0053-0.

26. Statistisches Bundesamt: Bevölkerung und Erwerbstätigkeit. Natürliche Bevölkerungsbewegung. 2012. [https://www.destatis.de/DE/ Publikationen/Thematisch/Bevoelkerung/Bevoelkerungsbewegung/ Bevoelkerungsbewegung2010110127004.pdf?_blob=publicationFile]. Accessed 30 June 2015.

27. Roch A, Wiramus S, Pauly V, Forel JM, Guervilly C, Gainnier M, et al. Longterm outcome in medical patients aged 80 or over following admission to an intensive care unit. Crit Care. 2011;15(1):R36. doi:10.1186/cc9984.
28. Tabah A, Philippart F, Timsit JF, Willems V, Francais A, Leplege A, et al. Quality of life in patients aged 80 or over after ICU discharge. Crit Care. 2010;14(1):R2. doi:10.1186/cc8231.

29. Puchades R, Gonzalez B, Contreras M, Gullon A, de Miguel R, Martin D, et al. Cardiovascular profile in critically ill elderly medical patients: prevalence, mortality and length of stay. Eur J Intern Med. 2015;26(1):49-55. doi:10.1016/j.ejim.2014.12.010.

30. Heyland DK, Garland A, Bagshaw SM, Cook D, Rockwood K, Stelfox HT, et al. Recovery after critical illness in patients aged 80 years or older: a multi-center prospective observational cohort study. Intensive Care Med. 2015;41(11):1911-20. doi:10.1007/s00134-015-4028-2.

31. Geppert A. Patients in the intensive care unit with valvular diseases. Med Klin Intensivmed Notfmed. 2013;108(7):555-60. doi:10.1007/ s00063-012-0140-z.

32. Kaarlola A, Tallgren M, Pettila V. Long-term survival, quality of life, and quality-adjusted life-years among critically ill elderly patients. Crit Care Med. 2006;34(8):2120-6. doi:10.1097/01.CCM.0000227656.31911.2E.

\section{Submit your manuscript to a SpringerOpen ${ }^{\odot}$ journal and benefit from:}

- Convenient online submission

- Rigorous peer review

- Immediate publication on acceptance

- Open access: articles freely available online

- High visibility within the field

- Retaining the copyright to your article

Submit your next manuscript at $>$ springeropen.com 